OPEN ACCESS

Edited by:

Anne-Mieke Vandamme,

KU Leuven, Belgium

Reviewed by:

Brian Godman,

Karolinska Institutet (KI), Sweden

Rafael T. Mikolajczyk,

Martin Luther University of

Halle-Wittenberg, Germany

*Correspondence:

Iftikhar All

iftikharalijan@gmail.com

Specialty section:

This article was submitted to Infectious Diseases - Surveillance,

Prevention and Treatment,

a section of the journal

Frontiers in Public Health

Received: 04 October 2017

Accepted: 25 May 2018

Published: 27 June 2018

Citation:

Ali I, Ijaz M, Rehman IU, Rahim A and Ata $H$ (2018) Knowledge, Attitude,

Awareness, and Barriers Toward Influenza Vaccination Among Medical

Doctors at Tertiary Care Health

Settings in Peshawar, Pakistan-A

Cross-Sectional Study.

Front. Public Health 6:173.

doi: 10.3389/fpubh.2018.00173

\section{Knowledge, Attitude, Awareness, and Barriers Toward Influenza Vaccination Among Medical Doctors at Tertiary Care Health Settings in Peshawar, Pakistan-A Cross-Sectional Study}

\author{
Iftikhar Ali ${ }^{1,2,3 *}$, Muhammad ljaz ${ }^{4}$, Inayat U. Rehman ${ }^{5,6}$, Afaq Rahim $^{7}$ and Humera Ata ${ }^{8}$ \\ ${ }^{1}$ Department of Pharmacy, University of Swabi, Swabi, Pakistan, ${ }^{2}$ Department of Pharmacy Services, Northwest General \\ Hospital and Research Center, Peshawar, Pakistan, ${ }^{3}$ Paraplegic Center, Peshawar, Pakistan, ${ }^{4}$ Department of Medicine, Gajju \\ Khan Medical College, Swabi, Pakistan, ${ }^{5}$ School of Pharmacy, Monash University Malaysia, Bandar Sunway, Malaysia, \\ ${ }^{6}$ Department of Pharmacy, Abdul Wali Khan University Mardan, Mardan, Pakistan, ${ }^{7}$ Department of Medicine, Khyber \\ Teaching Hospital, Peshawar, Pakistan, ${ }^{8}$ Department of International Maternal and Child Health, Uppsala University, Uppsala, \\ Sweden
}

Objective: This study intends to evaluate the knowledge, attitude and awareness of medical doctors toward influenza vaccination and the reasons for not getting vaccinated.

Methods: A cross-sectional study was carried out among medical doctors in three major tertiary care health settings in Peshawar, Khyber Pakhtunkhwa (KP), Pakistan. A web-based, pre-tested questionnaire was used for data collection.

Results: A total of $(n=300)$ medical doctors were invited, however only $(n=215)$ participated in the study with a response rate of $71.7 \%$. Among the participants, $95.3 \%(n=205)$ were males with a mean age of $28.67 \pm 3.89$ years. By designation, $121(56.3 \%)$ were trainee medical officers and 40 (18.6\%) were house officers. The majority $102(47.4 \%)$ had a job experience of $1-2$ years. Of the total sample, $38(17.7 \%)$ doctors reported having received some kind of vaccination, whereas only 19 (8.84\%) were vaccinated against influenza. The results identified that the major barriers toward influenza vaccinations included (1) Unfamiliarity with Influenza vaccination availability (Relative Importance Index RII = 0.830), (2) Unavailability of Influenza vaccines due to lack of proper storage area in the institution $(R \|=0.634)$, (3) Cost of vaccine $(R \|=0.608)$, and (4) insufficient staff to administer vaccine $(R \|=0.589)$. Additionally, $156(72.6 \%)$ of doctors were not aware of the influenza immunization recommendation and guidelines published by the Advisory Committee on Immunization Practices (ACIP) and Centre for Disease Control and Prevention (CDC). Physicians obtained a high score (8.27 \pm 1.61) of knowledge and understanding regarding influenza and its vaccination followed by medical officers $(8.06 \pm 1.37)$. Linear Regression analysis revealed that gender was significantly associated with the knowledge score with males having a higher score $(8.0 \pm$ 1.39) than females $(6.80 \pm 1.61 \beta=-1.254$ and $\mathrm{Cl}[-2.152$ to -0.355$], p=0.006)$. 


\begin{abstract}
Conclusion: A very low proportion of doctors were vaccinated against influenza, despite the published guidelines and recommendations. Strategies that address multiple aspects like increasing awareness and the importance of the influenza vaccine, the international recommendations and enhancing access and availability of the vaccine are needed to improve its coverage and health outcomes.
\end{abstract}

Keywords: Healthcare professionals, medical doctors, attitude, awareness, influenza, influenza vaccination, knowledge, Pakistan

\section{INTRODUCTION}

Influenza vaccination is the most efficient method of prevention of influenza virus infection and its complications (1, 2). Influenza is a common, highly contagious disease and healthcare professionals (HCPs) are at increased risk of getting infected and serve as carriers for transmission to other patients (3-5). Immunization against influenza virus not only reduces the risk of infection among HCPs, but also improves patient safety and reduces morbidity and mortality among vulnerable patients (3).

Influenza transmission within health care settings have been widely reported in medical literature (6). Therefore, both the World Health Organization (WHO) and the Strategic Advisory Group of Experts (SAGE) on Immunization recommend seasonal and pandemic influenza vaccination for $\operatorname{HCPs}(7,8)$. Despite these guidelines and recommendations, vaccination coverage among HCPs has remained low, with little improvement during the pandemic of influenza A (H1N1) in 2009 (9). The scenario is more or less similar in European countries (10). Despite a variety of promotional campaigns and interventions, influenza vaccination acceptance among HCPs generally remains abysmal and most studies report poor adherence to this recommendation (11). The current rate of influenza vaccination for most health care settings remains at a meager $42 \%$ (12, 13). This low coverage might be attributable to apprehension regarding the effectiveness of the vaccine and concerns about adverse effects (12). Nevertheless, comprehending these barriers are important in controlling the low adherence to the recommendations for vaccination $(7,13,14)$.

A literature search showed only one published study in 2016 among HCPs (Physicians, Pharmacists, Nurses, and Physiotherapists etc.) in private tertiary care settings in Peshawar on this subject which revealed poor knowledge of respondents toward influenza and its prevention (13). It also revealed misconceptions about influenza vaccine among the respondents (13). Therefore, this study fills the knowledge gap and aims to determine the vaccination rate and identify the factors influencing influenza vaccination among the doctors in tertiary care health settings in KP, Pakistan. The findings of this study can help in planning strategies to improve the situation and

\footnotetext{
Abbreviations: HCPs, Healthcare professionals; WHO, World Health Organization; SAGE, Strategic Advisory Group of Experts; HMC, Hayatabad Medical Complex; LRH, Lady Reading Hospital; KTH, Khyber Teaching Hospital; CDC, Centre for Disease Control and Prevention; ACIP, Advisory Committee on Immunization Practices.
}

provide constructive steps toward future recommendations for vaccinating HCPs in Pakistan.

\section{MATERIALS AND METHODS}

\section{Study Design}

A cross-sectional study among medical doctors was carried out in three major tertiary care hospitals in Peshawar, KP, Pakistan, from 20th March to 26th May 2016. The three tertiary care hospitals, namely: Hayatabad Medical Complex (HMC); Lady Reading Hospital (LRH); and Khyber Teaching Hospital (KTH), constitute the major public health facilities in Peshawar, the capital of Khyber Pakhtunkhwa. A previously validated (Cronbach's alpha $=0.87$ ), self-administered, webbased questionnaire was circulated online using the Google forms platform. The questionnaire included 31 items (three sections) that collected information about the demographics (age, gender, designation, type of ward, job experience, and hospital), knowledge of influenza virus and vaccination, current practice and awareness of published guidelines. The link to the online survey was sent through email and popular social networks (Facebook, WhatsApp) to medical doctors. Those who followed the link were asked to affirm their agreement to participate in the survey. The study aimed to recruit at least 300 medical doctors in three tertiary care health settings, however 215 participated in this study. Due to the pilot nature of this study no formal sample size calculation was conducted.

\section{Ethics Approval}

The study protocol was approved by Bacha Khan Medical Complex (Teaching Hospital of Gajju Khan Medical College), Shah Mansoor, Swabi, KP, Pakistan (Reference Number, EC5/6/17).

\section{Questionnaire Items}

A 31-item questionnaire was used to attain the objectives of the study. The questionnaire was adopted from existing literature addressing the same research question in other regions (12). The questionnaire comprised of three sections;

- The first section comprised of eight items aiming to inquire about the demographic information of doctors and their disclosure by asking whether they have been vaccinated against influenza or any other disease.

- The second section consisted of eight items, inquiring about the reasons for not receiving vaccination against influenza. 
A five-item Likert-scale was provided to choose the relevant response.

- The third section comprised of four items aiming to explore the doctors' general understanding about influenza vaccination.

- The last part, or section three, of the questionnaire was related to the knowledge of influenza and influenza vaccines. It comprised of 11 statements, a nominal scale of correct and incorrect was provided for the doctors' convenience to disclose their response (Data Sheet 1).

\section{Statistical Analysis}

For data analysis, SPSS ${ }^{\circledR}$ V 20.0 (IBM Corp., Armonk, NY, USA) was used. Frequency and Percentages were used for categorical variables. A Fisher exact test was applied to identify the significant factors hindering influenza vaccination. Additionally, to identify the top four barriers toward influenza vaccination among doctors, a Relative Importance Index (RII) $(15,16)$ was calculated for each of the eight statements. "RII is a commonly used method to obtain priority rankings of attributes and it is particularly useful where a structured questionnaire is used to solicit measurements that are subjective in nature" (17) The RIIs is calculated by the formula shown in Equation (1.0) (18).

$$
\mathrm{RII}=\left(1 \mathrm{n}_{1}+2 \mathrm{n}_{2}+3 \mathrm{n}_{3}+4 \mathrm{n}_{4}+5 \mathrm{n}_{5}\right) / 5 \mathrm{~N}(0 \leq \mathrm{RII} \leq 1)
$$

Where: $N=$ Total number of respondent, $5=$ highest weighted score $(1,2,3,4,5)$ on Likert scale where: $\mathrm{n} 1=$ number of participants who selected "strongly disagree," n2 = number of participants who selected "disagree," n3 = number of participants who selected "do not know," n4 = number of participants who selected "agree," and n5 = number of participants who selected "strongly agree." The score for each factor is calculated by summing up the scores given to it by the participants.

The mean item score was used to rank top four barriers. The 5-point Likert scale was converted to index for each barrier, which made it possible to cross-compare the relative importance of each of the barriers as supposed by the participants. The value of the RII ranges from 0 to 1 (17), a value closest to 1 ranked as the main barrier to influenza vaccination compared to others. For the 11 items regarding the knowledge (Table 4), scoring of the responses was done using 1 and 0 for correct and incorrect responses respectively. To identify the contributing factors affecting the knowledge score, linear regression analysis was conducted using score as the dependent variable while using age, gender, designation, and job experience as the independent variables. Moreover, Mann-Whitney and Kruskul Wallis test were used to closely notice the differences in knowledge among the groups. A $P$-value of $<0.05$ was set significant for all of the statistical tests.

\section{RESULTS}

A total of $n=300$ medical doctors were invited, however $n=215$ participated in this study and the response rate was $71.7 \%$. The mean age was $28.67 \pm 3.89$ years and the majority were males, $n=205$ (95.3\%). By designation, 121(56.3\%) were trainee medical officers, 40 (18.6\%) were house officers and 36 (16.7\%) medical officers. A majority of the doctors $102(47.4 \%)$ had a job experience of $1-2$ years followed by 52 (24.2\%) with $3-5$ years job experience. Only $17.7 \%$ of the doctors had history of vaccination in the past 6-12 months for other diseases, of which influenza vaccine comprised $50 \%$ (Table 1 ).

While evaluating the doctors' justifications for not being vaccinated against influenza, $\sim 78.1 \%$ of the respondents disagreed that influenza is not serious condition therefore not worth vaccinating, however, $13.49 \%$, believed that it is not compulsory for HCPs to get vaccinated for influenza. None of the statements was associated with uptake of vaccination against influenza. Upon calculation of the RII, the top four barriers identified were: "Not everyone is familiar with Influenza vaccination availability at their institutions" ( $R I I=0.830)$, "There is lack of proper storage area for vaccines that's why Influenza

TABLE 1 | Demographics of Respondents $(N=215)$.

\begin{tabular}{|c|c|}
\hline Demographics & $\mathbf{N}(\%)$ \\
\hline \multicolumn{2}{|l|}{ Age } \\
\hline Range & 24 years -65 years \\
\hline Mean age $\pm S D$ & $28.67 \pm 3.89$ years \\
\hline \multicolumn{2}{|l|}{ Gender } \\
\hline Male & 205 (95.3\%) \\
\hline Female & $10(04.7 \%)$ \\
\hline \multicolumn{2}{|l|}{ Job experience } \\
\hline Less than 1 year & $30(14.0 \%)$ \\
\hline $1-2$ years & $102(47.4 \%)$ \\
\hline $3-5$ years & $52(24.2 \%)$ \\
\hline $6-10$ years & $31(14.4 \%)$ \\
\hline \multicolumn{2}{|l|}{ Hospitals } \\
\hline Lady Reading Hospital, Peshawar & 44 (20.5\%) \\
\hline Hayatabad Medical Complex, Peshawar & $48(22.3 \%)$ \\
\hline Khyber teaching Hospital, Peshawar & $123(57.2 \%)$ \\
\hline \multicolumn{2}{|l|}{ Type of ward } \\
\hline Medicine & $140(65.1 \%)$ \\
\hline Surgery & 75 (34.9\%) \\
\hline \multicolumn{2}{|l|}{ Designations } \\
\hline Trainee medical officer & $121(56.3 \%)$ \\
\hline Medical Officer & $36(16.7 \%)$ \\
\hline House Officer & $40(18.6 \%)$ \\
\hline Registrar & 07 (3.3\%) \\
\hline Physicians & $11(5.11 \%)$ \\
\hline \multicolumn{2}{|c|}{ Vaccination done in last 6-12 months against any disease } \\
\hline Yes & $38(17.7 \%)$ \\
\hline No & $114(53.02 \%)$ \\
\hline Never vaccinated in last 2-3 years' time & $63(29.30 \%)$ \\
\hline \multicolumn{2}{|c|}{ Vaccination done in last 6-12 months against influenza } \\
\hline Yes & 19 (8.84\%) \\
\hline No & $196(91.16 \%)$ \\
\hline \multicolumn{2}{|c|}{ Name the disease for which you have done vaccination } \\
\hline Influenza & $19(50 \%)$ \\
\hline Hepatitis & $17(44.74 \%)$ \\
\hline Tetanus toxoid & $01(2.63 \%)$ \\
\hline Anti-Rabies & $01(2.63 \%)$ \\
\hline
\end{tabular}


vaccines are not available in the institution" (RII $=0.634)$, "Influenza vaccine is costly that's why not purchased normally" $(R I I=0.608)$ and "There is insufficient staff to administer vaccine" $(R I I=0.589)$ as shown in (Table 2).

Regarding the general understanding of doctors about influenza vaccine, $145(67.4 \%)$ responded that "the influenza vaccine is effective in preventing the flu", while $116(54.0 \%)$ responded that " $C D C$ recommends that healthcare professionals receive the flu shot". About 165 (72.6\%) participants were not "aware of the guidelines published by the ACIP or CDC for influenza immunization" and regarding the influenza vaccination schedule. A majority of $61.9 \%$ of the doctors thought that "influenza vaccine is to be administered once in life" (Table 3).

Table 4 depicts the doctors knowledge toward influenza and influenza vaccine. It is revealed that $79(36.7 \%)$ of the doctors had a misconception regarding the composition of influenza vaccines; 129(60.0\%) believed that the "flu shot contains a live virus that may cause influenza". Moreover, a majority, 161(74.9\%), believed that "symptoms usually appear 8-10 days after a person is exposed to influenza". Nearly $38.1 \%$ believed that people "with influenza can transmit the infection only after their symptoms appear" and about 57(26.5\%) believed "HCPs can not spread influenza even when they are feeling well". About 62(28.8\%) believed that "nausea and vomiting, or diarrhea, are common symptoms observed during an influenza infection". In addition, 40(18.6\%) of the doctors believe that Influenza is transmitted primarily by contact with blood and body fluids.

Among the participants the knowledge and understanding about influenza vaccination did not differ significantly with physicians gaining a slightly higher score $(8.27 \pm 1.61)$ then medical officers $(8.06 \pm 1.37)$ and trainee medical officers (8.02 \pm 1.39 ). Doctors with job experience of 6-10 years had better knowledge about influenza vaccination $(8.19 \pm 1.30)$ compared to doctors with less than 1 year job experience $(7.87 \pm 1.38)$. Additionally, male doctors possessed better knowledge (8.05 $\pm 1.39, P=0.003$ ) than female doctors as shown (Table 5).

Linear regression was applied using sum of 11 items score as the dependent variable and age, gender, designation and job experience as the independent variable. Overall, gender was found to be a significant predictor of the total knowledge score and males had a higher score than the females with $\beta=-1.254$ and CI $[-2.152$ to -0.355$], p=0.006$; while age, job experience and designation were observed to be insignificant factors of the overall doctors' knowledge as shown in (Table 6).

\section{DISCUSSION}

Compliance of HCPs to influenza vaccination is a matter of intense debate. The present study is perhaps the first-of-itskind to evaluate Pakistani medical doctors' knowledge, and attitude toward influenza vaccination in public sector tertiary care health settings in Peshawar, Khyber Pakhtunkhwa as a previous study in Pakistan investigated knowledge and attitude to influenza vaccination in all health care professionals in a private setup (13). It is evident from several published studies that vaccinating HCPs against influenza is an effective intervention to protect against infections, reduce its transmission to the patients and to decrease mortality and morbidity among the vulnerable

TABLE 2 | Reason for not vaccination against influenza.

\begin{tabular}{|c|c|c|c|c|c|c|c|c|}
\hline Statements & SDA & DA & DK & A & SA & $P$-value & RII & Rank \\
\hline $\begin{array}{l}\text { There is lack of proper storage } \\
\text { area for vaccines that's why } \\
\text { Influenza vaccines are not } \\
\text { available in the institution }\end{array}$ & 07 (3.3\%) & 40 (18.6\%) & 100 (46.5\%) & 46 (21.4\%) & 22 (10.2\%) & 0.454 & 0.634 & 2 \\
\hline $\begin{array}{l}\text { It is not compulsory for health } \\
\text { care professionals to get } \\
\text { vaccinated for Influenza }\end{array}$ & 58 (27.0\%) & 89 (41.4\%) & 39 (18.1\%) & 21 (9.8\%) & 8 (3.7\%) & 0.600 & 0.444 & 7 \\
\hline $\begin{array}{l}\text { Influenza is not serious condition } \\
\text { therefore not worth vaccinating } \\
\text { against }\end{array}$ & 50 (23.3\%) & 118 (54.9\%) & 18 (8.4\%) & 28 (13.0\%) & 1 (0.5\%) & 0.446 & 0.425 & 8 \\
\hline $\begin{array}{l}\text { Influenza vaccine is costly that's } \\
\text { why not purchased normally }\end{array}$ & 14 (6.5\%) & 38 (17.7\%) & 100 (46.5\%) & $51(23.7 \%)$ & 12 (5.6\%) & 0.170 & 0.608 & 3 \\
\hline $\begin{array}{l}\text { Not everyone is familiar with } \\
\text { Influenza vaccination availability at } \\
\text { their institutions }\end{array}$ & 02 (0.9\%) & 09 (4.2\%) & 11 (5.1\%) & 126 (58.6\%) & 67 (31.2\%) & 0.725 & 0.830 & 1 \\
\hline $\begin{array}{l}\text { There is insufficient staff to } \\
\text { administer vaccine }\end{array}$ & 12 (5.6\%) & 76 (35.3\%) & 49 (22.8\%) & 68 (31.6\%) & $10(4.7 \%)$ & 0.303 & 0.589 & 4 \\
\hline $\begin{array}{l}\text { Side effects and safety concerns } \\
\text { are hindering health care } \\
\text { professionals to get vaccinated } \\
\text { for influenza }\end{array}$ & 14 (6.5\%) & 105 (48.8\%) & 55 (25.6\%) & 36 (16.7\%) & 5 (2.3\%) & 0.080 & 0.519 & 5 \\
\hline $\begin{array}{l}\text { Due to needle fear I don't like to } \\
\text { get vaccinated }\end{array}$ & 29 (13.5\%) & 125 (58.1\%) & 11 (5.1\%) & 39 (18.1\%) & $11(5.1 \%)$ & 0.064 & 0.487 & 6 \\
\hline
\end{tabular}

Fischer exact test was applied; SDA, strongly disagree; DA, Disagree; DK, Don't Know; A, Agree; SA, strongly agree; RIl, Relative importance index. 
patients $(2,13,19)$. Vaccination also reduces absenteeism and improves the health status of HCPs $(6,11,20,21)$. However, this study reveals low rates of immunization against influenza among the doctors in tertiary care health settings of Peshawar, Pakistan, despite the ACIP and CDC recommendations and HCPs being at higher risk of infection. These findings are in line with some published studies that described a lower rate of influenza immunization among $\operatorname{HCPs}(13,22)$. Moreover, influenza vaccination rate among doctors figured by the present study is, probably, the lowest among HCPs compared with

TABLE 3 | Medical doctors' general understanding about the influenza vaccine.

\begin{tabular}{lc}
\hline Statement & $\boldsymbol{N}(\%)$ \\
\hline $\begin{array}{l}\text { Do you think the influenza vaccine is effective in preventing } \\
\text { the 'flu? }\end{array}$ \\
Yes & $145(67.4 \%)$ \\
No & $14(6.5 \%)$ \\
Not Sure & $56(26.0 \%)$ \\
Do you believe that the Centre for Disease Control (CDC) \\
recommends that healthcare professionals receive the flu \\
shot? \\
Yes \\
No \\
Not sure & $116(54.0 \%)$ \\
Are you aware of the guidelines published by the Advisory & $23(10.7 \%)$ \\
Committee on Immunization Practices (ACIP) or CDC for & $76(35.3 \%)$ \\
influenza immunization? & \\
Yes & \\
No & $34(15.8 \%)$ \\
Not sure & $156(72.6 \%)$ \\
How often do you think the flu vaccine should be & $25(11.6 \%)$ \\
administered? & \\
Every year & \\
Once in life & \\
Every 6 months & $21(9.8 \%)$ \\
Every 5 years & $133(61.9 \%)$ \\
Never & $51(23.7 \%)$ \\
& $8(3.7 \%)$ \\
& $2(0.9 \%)$ \\
\end{tabular}

available literature from different region of the world i.e., "Kuwait (67.2\%) Oman (46.4\%), Kingdom of Saudi Arabia [KSA (38.0\%) and United Arab Emirates $\operatorname{UAE}(24.7 \%)]$ ]" $(12,13)$.

The proportions of HCPs who have been vaccinated against influenza are quite low in Pakistan, which has been justified in a recent study among HCPs done in Peshawar to investigate knowledge, awareness and attitude toward influenza vaccination $(13,23)$. The low uptake of influenza immunization among practicing doctors in the present study seems to be related to unfamiliarity with influenza vaccination, cost and understanding. Our survey was unable to show a consistent positive correlation between HCPs' perception of efficacy of the influenza vaccine and the choice to be vaccinated. Conversely, our study showed that $67.4 \%$ of the study sample was aware that the vaccine was effective in preventing influenza with a low self-declared vaccination rate.

It is essential to understand the factors that affect HCPs compliance toward influenza vaccines. One study revealed that HCPs' fear of adverse reaction may act as one of the main barriers to vaccination (24). Moreover, it is also noticed that about $10-45 \%$ of HCPs feared getting vaccinated induced influenza $(13,25)$. Surprisingly, $06-58 \%$ of HCPs from technologically advanced countries like Switzerland and Canada believed that they were healthy and they preferred to have good natural defense toward influenza infection (25-28). Comparing the result of this study to that of developed countries, the fear of side effects was only disclosed by $19.1 \%$ of the respondents and the rest disagreed with the statement that side effect and safety concerns might hinder HCPs willingness to get a flu shot. Hofmann et al. showed that in some cases, approximately $54.0 \%$ of HCPs believed that they may suffer adverse drug reactions, which was the main reason for their reluctance to get vaccinated (24). In the current sample, it was revealed that the main barrier to influenza vaccination among HCPs is the unfamiliarity with Influenza vaccination availability, cost and lack of proper storage area for vaccine at their institutions. These findings are in agreement to the results reported in studies conducted by Khan TM et al. in Pakistan (13) and James, P B et al. in Sierra Leone (29) in which lack of awareness about the vaccine availability at their institution, high cost of the

TABLE 4 | Knowledge of medical doctors about influenza and the influenza vaccine.

\begin{tabular}{|c|c|c|}
\hline Statement & Correct & Incorrect \\
\hline Q1. Health care professionals are less susceptible to influenza infections than other people & $17(7.9 \%)$ & $198(92.1 \%)^{\star \star}$ \\
\hline Q2. Influenza is transmitted primarily by coughing and sneezing & $210(97.7 \%)^{\star \star}$ & $5(2.3 \%)$ \\
\hline Q3. Influenza is more serious than a "common cold & $203(94.4 \%)^{* *}$ & $12(5.6 \%)$ \\
\hline Q4. The signs and symptoms of influenza include fever, headache, sore throat, cough, nasal congestion, and aches and pains & $213(99.1 \%)^{\star \star}$ & $2(0.9 \%)$ \\
\hline Q5. HCPs can spread influenza even when they are feeling well. & $158(73.48 \%)^{\star \star}$ & $57(26.5 \%)$ \\
\hline Q6. People with influenza can transmit the infection only after their symptoms appear & $82(38.1 \%)$ & $133(61.9 \%)^{\star \star}$ \\
\hline Q7. Influenza is transmitted primarily by contact with blood and body fluids & $40(18.6 \%)$ & $175(81.4 \%)^{\star *}$ \\
\hline Q8. The flu shot contains live viruses that may cause some people to get influenza & $129(60.0 \%)$ & $86(40.0 \%)^{\star \star}$ \\
\hline Q9. Influenza vaccination does not work in some persons, even if the vaccine has the right mix of viruses & $136(63.3 \%)^{\star \star}$ & $79(36.7 \%)$ \\
\hline Q10. Adults with influenza commonly experience nausea and vomiting or diarrhea & $62(28.8 \%)$ & $153(71.2 \%)^{\star *}$ \\
\hline Q11. Symptoms typically appear $8-10$ days after a person is exposed to influenza & $161(74.9 \%)$ & $54(25.1 \%)^{\star \star}$ \\
\hline
\end{tabular}

${ }^{* *}$ Correct statement, Score range 1-11. 
vaccine and lack of awareness were put forward by participants as barriers to influenza vaccinations. Other barrier to influenza vaccinations identified in this study included the fear of needles and the side-effects, lack of sufficient staff to administer vaccine and safety concerns associated with influenza vaccinations. Fear of needle and concerns about side-effects of the vaccine are also some of the reasons that have been reported in other studies $(12,13,20)$. In the current study, about $23.2 \%$ of the respondents disclosed their unwillingness to vaccinations due to fear of needles. Similarly, a study by Hofmann et al. (24) reported 4-26\% of HCPs with fear of injections. These knowledge gaps are essential to be addressed among Pakistani HCPs, and such wrong beliefs are perhaps due to the lack of any health campaigns among the HCPs to create awareness about influenza vaccination. Most HCPs had basic knowledge of the influenza vaccine and infection and most participating doctors were aware that people with asymptomatic influenza can transmit influenza (61.9\%); a study conducted in Iran by Khazaeipour et al.'s reported similar beliefs among HCPs, with only $32.4 \%$ of HCPs stating that people with asymptomatic influenza can transmit influenza (30).

Furthermore, our data showed variable levels of knowledge about influenza vaccination. Nearly $97.7 \%$ of the doctors have

TABLE 5 | Medical doctors score for knowledge about Influenza and the influenza vaccine against gender, designation, and job experience.

\begin{tabular}{lll}
\hline Variable & Mean \pm SD & p-value \\
\hline Gender & & $0.003^{* a}$ \\
Male & $8.05 \pm 1.39$ & \\
Female & $6.80 \pm 1.61$ & $0.469^{b}$ \\
Designation & & \\
House Officer & $7.95 \pm 1.60$ & \\
Medical Officer & $8.06 \pm 1.37$ & \\
Trainee medical officer & $8.02 \pm 1.39$ & $0.774^{b}$ \\
Registrar & $7.14 \pm 1.39$ & \\
Physicians & $8.27 \pm 1.61$ & \\
Job experience & & \\
Less than 1 year & $7.87 \pm 1.38$ & \\
1-2 years & $7.89 \pm 1.48$ & \\
3-5 years & $8.15 \pm 1.42$ & \\
6-10 years & $8.19 \pm 1.30$ & \\
\hline
\end{tabular}

a Mann-Whitney test. ${ }^{b}$ Kruskul Wallis test. ${ }^{\star} P$-values $<0.05$ was considered significant. a belief that Influenza is transmitted primarily by coughing and sneezing; broadly in line with other studies (13, 22, 31-33). A similar level of response (90.61\%) was seen by Alshammari TM (12). Moreover, $99.1 \%$ have a proper understanding about the symptoms of influenza and 153(71.2\%) expressed that symptoms such as nausea and vomiting or diarrhea are common in influenza infection among adults. Furthermore, $60.0 \%$ of all participants in this study shared a view that influenza vaccine is infectious and can cause influenza. Previous studies have presented various rates of belief amongst HCPs that the influenza vaccine can cause influenza infection (38.1-78\%) (3235 ). Only $15.8 \%$ of the doctors were familiar with the influenza immunization program for HCPs. A number of studies have described that in KSA, nearly $86 \%$ of the respondents were familiar with the recommendation of ACIP and in the 3 Middle-East countries: Kuwait, Oman, and UAE, nearly 49\% of HCPs were knowledgeable of the CDC recommendations regarding seasonal influenza vaccination $(1,12,36)$. We noted much lower perception of these guidelines in our study sample; around $72.6 \%$ of participating doctors were not aware of the CDC or ACIP recommendations. In our study, physicians were found to have a good knowledge of the influenza symptoms and vaccinations, followed by the medical officers. In addition, participants with a job experience of 6-10 years were seen to have a significantly better knowledge as compared to others.

Some other studies conducted in the Asian countries have also provided medium to low correlation of gender and age with the individual questions presented to evaluate attitudes and knowledge of HCPs toward influenza vaccination (13, 32, 36 ), though, when sum of knowledge items was tested to see the factors affecting the knowledge score, gender was found to be another significant factor affecting the knowledge score of doctors.

After assessing the attitude and knowledge toward vaccination, a foresighted level was observed among Pakistani doctors. Already the education level of the doctors is fair enough but still a robust plan is needed to be implemented at government level to highlight the need and importance of influenza vaccination and the government should work to include influenza vaccination in national immunization programs. Additionally, a regular monthly newsletter should be circulated by the ministry of health to all practicing HCPs in order to educate them and make them aware of the influenza vaccination availability at hospitals and free the cost for the

TABLE 6 | Factors affecting the Knowledge score of Medical doctors.

\begin{tabular}{lcrr}
\hline Variable & Regression coefficient $(\boldsymbol{\beta})[95 \%$ Cl] & Std. error & $\boldsymbol{p}$-value \\
\hline Age & $0.039[-0.009$ to 0.088$]$ & 1.614 & 0.024 \\
Gender & $-1.254[-2.152$ to -0.355$]$ & -2.750 & 0.456 \\
Designation & $0.141[-0.0073$ to 0.355$]$ & 1.299 & 0.108 \\
Job experience & $0.008[-0.186$ to 0.202$]$ & 0.077 & 0.098 \\
\hline
\end{tabular}

Linear regression was applied using score as a dependent variable and age, gender, designation, and job experience as independent variable. $P$-values $<0.05$ were considered statistically significant. 
general masses in order to cope with influenza spread, thus supporting good health retention in HCPs and stopping the spread of such diseases to patients.

\section{CONCLUSION}

Despite the published guidelines and recommendations, a very low proportion of doctors in the three tertiary care health settings of Peshawar were vaccinated against influenza. The barriers and misconceptions about influenza and vaccines should be reduced through multiple strategies, which include organizing seminars on awareness regarding vaccinations. This is required to improve the understanding and general results. Pakistani health authorities need to inspire all HCPs to receive vaccination and improve their degree of compliance with recommendations for immunization against influenza by announcing it as mandatory for all HCP's working in health settings. Furthermore, implementation of an occupational health department in each tertiary hospital overseeing vaccination status would also help keep track of and ensure adequate compliance amongst HCPs.

\section{REFERENCES}

1. Rehmani R, Memon JI. Knowledge, attitudes and beliefs regarding influenza vaccination among healthcare workers in a Saudi hospital. Vaccine (2010) 28:4283-7. doi: 10.1016/j.vaccine.2010.04.031

2. National Vaccine Advisory Committee. Strategies to achieve the healthy people 2020 annual influenza vaccine coverage goal for health-care personnel: recommendations from the national vaccine advisory committee. Public Health Rep. (2013) 128:7-25. doi: 10.1177/003335491312800103

3. Talbot TR, Babcock H, Caplan AL, Cotton D, Maragakis LL, Poland GA, et al. Revised SHEA position paper: influenza vaccination of healthcare personnel. Infect Control Hosp Epidemiol. (2010) 31:987-95. doi: 10.1086/656558

4. Poland GA. The 2009-2010 influenza pandemic: effects on pandemic and seasonal vaccine uptake and lessons learned for seasonal vaccination campaigns. Vaccine (2010). 28(Suppl. 4):D3-13. doi: 10.1016/j.vaccine.2010.08.024

5. Jordan R, Hayward A. Should healthcare workers have the swine flu vaccine? BMJ (2009) 339:b3398. doi: 10.1136/bmj.b3398

6. Fortaleza CR, Fortaleza CMCB. Knowledge and attitudes of health care workers from intensive care units regarding nosocomial transmission of influenza: a study on the immediate pre-pandemic period. J Venom Anim Toxins Incl Trop Dis. (2011) 17:168-75. doi: 10.1590/S1678-91992011000200007

7. World Health Organization. Influenza vaccines: WHO position paper. Wkly Epidemiol Rec. (2005) 80:279-87.

8. World Health Organization. Strategic Advisory Group of Experts on Immunization-report of the extraordinary meeting on the influenza A (H1N1) 2009 pandemic, 7 July 2009. Wkly Epidemiol Rec. (2009) 84:301-4.

9. Bellia C, Setbon M, Zylberman P, Flahault A. Healthcare worker compliance with seasonal and pandemic influenza vaccination. Influenza Other Respir Viruses (2013) 7:97-104. doi: 10.1111/irv.12088

10. Ciancio BC, Rezza G. Costs and benefits of influenza vaccination: more evidence, same challenges. BMC Public Health (2014) 14:818. doi: $10.1186 / 1471-2458-14-818$

11. Mallari J, Goad J, Joanne W, Johnson K, Forman T, Neinstein L. Knowledge, attitudes, and practices regarding influenza vaccination among health professional students. J Am Pharm Assoc. (2007) 47:498-502. doi: 10.1331/JAPhA.2007.07018

\section{AUTHOR CONTRIBUTIONS}

Conception and design: IA, MI. Data collection: MI, IA. Data analysis and interpretation, Results: IA, IR, HA. Manuscript drafting and writing: IA, MI, IR, AR. Language editing, appropriateness, critical revision: AR, HA, IA. All authors read and approved the final version of the paper.

\section{ACKNOWLEDGMENTS}

We would like to acknowledge all the doctors who participated in this study. We would also like to express our great appreciation to Brekhna Hassan, Ph.D (Research Associate), Institute of Infection and Immunity, Cardiff University, United Kingdom for her contribution, feedback and input.

\section{SUPPLEMENTARY MATERIAL}

The Supplementary Material for this article can be found online at: https://www.frontiersin.org/articles/10.3389/fpubh. 2018.00173/full\#supplementary-material

12. Alshammari TM, AlFehaid LS, AlFraih JK, Aljadhey HS. Health care professionals' awareness of, knowledge about and attitude to influenza vaccination. Vaccine (2014) 32:5957-61. doi: 10.1016/j.vaccine.2014.08.061

13. Khan TM, Khan AU, Ali I, Wu DB-C. Knowledge, attitude and awareness among healthcare professionals about influenza vaccination in Peshawar, Pakistan. Vaccine (2016) 34:1393-8. doi: 10.1016/j.vaccine.2016.01.045

14. Lugo NR. Will carrots or sticks raise influenza immunization rates of health care personnel? Am J Infect Control (2007) 35:1-6. doi: 10.1016/j.ajic.2006.10.004

15. Kometa ST, Olomolaiye PO, Harris FC. Attributes of UK construction clients influencing project consultants' performance. Const Manag Econ. (1994) 12:433-43. doi: 10.1080/01446199400000053

16. Sambasivan M, Soon YW. Causes and effects of delays in Malaysian construction industry. Int $J$ Project Manag. (2007) 25:517-26. doi: 10.1016/j.ijproman.2006.11.007

17. Cheung S, Tam C, Ndekugri I, Harris F. Factors affecting clients' project dispute resolution satisfaction in Hong Kong. Const Manag Econ. (2000) 18:281-94. doi: 10.1080/014461900370654

18. Lim EC, Alum J. Construction productivity: issues encountered by contractors in Singapore. Int J Project Manag. (1995) 13:51-8. doi: 10.1016/0263-7863(95)95704-H

19. Bénet T, Régis C, Voirin N, Robert O, Lina B, Cronenberger S, et al. Influenza vaccination of healthcare workers in acute-care hospitals: a case-control study of its effect on hospital-acquired influenza among patients. BMC Infect Dis. (2012) 12:30. doi: 10.1186/1471-2334-12-30

20. Carman WF, Elder AG, Wallace LA, McAulay K, Walker A, Murray GD, et al. Effects of influenza vaccination of health-care workers on mortality of elderly people in long-term care: a randomised controlled trial. Lancet (2000) 355:93-7. doi: 10.1016/S0140-6736(99) 05190-9

21. Pearson ML, Bridges CB, Harper SA. Influenza vaccination of healthcare personnel. Recommendations of the Healthcare Infection Control Practices Advisory Committee (HICPAC) and the Advisory Committee on Immunization Practices (ACIP). MMWR Recomm Rep. (2006) 55:1-16.

22. Hiremath RN, Kotwal SA, Kunte R, Hiremath S, Basannar D, Bhalla S. Acceptance of vaccination against the 2009 pandemic influenza A among health-care workers in Pune, Maharashtra. Indian J Public Health (2013) 57:48. doi: 10.4103/0019-557X.111383 
23. Farrukh MJ, Ming LC, Zaidi ST, Khan TM. Barriers and strategies to improve influenza vaccination in Pakistan. J Infect Public Health (2017) 10:881-3. doi: 10.1016/j.jiph.2016.11.021

24. Hofmann F, Ferracin C, Marsh G, Dumas R. Influenza vaccination of healthcare workers: a literature review of attitudes and beliefs. Infection (2006) 34:142-7. doi: 10.1007/s15010-006-5109-5

25. Manuel D, Henry B, Hockin J, Naus M. Health behavior associated with influenza vaccination among healthcare workers in long-term-care facilities. Infect Control Hosp Epidemiol. (2002) 23:609-14. doi: 10.1086/501980

26. Ballada D, Biasio L, Cascio G, D’Alessandro D, Donatelli I, Fara G, et al. Attitudes and behavior of health care personnel regarding influenza vaccination. Eur J Epidemiol. (1994) 10:63-8. doi: 10.1007/BF01717454

27. Pachucki CT, Lentino JR, GG J. Attitudes and behavior of health care personnel regarding the use and efficacy of influenza vaccine. J Infect Dis. (1985) 151:1170-1. doi: 10.1093/infdis/151.6.1170

28. Harbarth S, Siegrist C-A, Schira J-C, Wunderli W, Pittet D. Influenza immunization: improving compliance of healthcare workers. Infect Control Hosp Epidemiol. (1998) 19:337-42. doi: 10.2307/30141375

29. James PB, Rehman IU, Bah AJ, Lahai M, Cole CP, Khan TM. An assessment of healthcare professionals' knowledge about and attitude towards influenza vaccination in Freetown Sierra Leone: a cross-sectional study. BMC Public Health (2017) 17:692. doi: 10.1186/s12889-017-4700-2

30. Khazaeipour Z, Ranjbarnovin N, Hoseini N. Influenza immunization rates, knowledge, attitudes and practices of health care workers in Iran. J Infect Dev Ctries. (2010) 4:636-44. doi: 10.3855/jidc.1152

31. Douville LE, Myers A, Jackson MA, Lantos JD. Health care worker knowledge, attitudes, and beliefs regarding mandatory influenza vaccination. Arch Pediatr Adol Med. (2010) 164:33-7. doi: 10.1001/archpediatrics.2009.252
32. Bali NK, Ashraf M, Ahmad F, Khan UH, Widdowson MA, Lal RB, et al Knowledge, attitude, and practices about the seasonal influenza vaccination among healthcare workers in Srinagar, India. Influenza Other Respir Viruses (2013) 7:540-5. doi: 10.1111/j.1750-2659.2012.00416.x

33. Wicker S, Rabenau HF. Vaccination rates of healthcare workers vary according to their occupational group. Procedia Vaccinol. (2011) 4:14-8. doi: 10.1016/j.provac.2011.07.003

34. Doebbeling BN, Edmond MB, Davis CS, Woodin JR, Zeitler RR. Influenza vaccination of health care workers: evaluation of factors that are important in acceptance. Prev Med. (1997) 26:68-77. doi: 10.1006/pmed.1996.9991

35. Nichol KL, Lind A, Margolis KL, Murdoch M, McFadden R, Hauge M, et al The effectiveness of vaccination against influenza in healthy, working adults. New Eng J Med. (1995) 333:889-93. doi: 10.1056/NEJM199510053331401

36. Abu-Gharbieh E, Fahmy S, Rasool BA, Khan S. Influenza vaccination: healthcare workers attitude in three Middle East countries. Int J Med Sci. (2010) 7:319-25. doi: 10.7150/ijms.7.319

Conflict of Interest Statement: The authors declare that the research was conducted in the absence of any commercial or financial relationships that could be construed as a potential conflict of interest.

Copyright (C) 2018 Ali, Ijaz, Rehman, Rahim and Ata. This is an open-access article distributed under the terms of the Creative Commons Attribution License (CC $B Y)$. The use, distribution or reproduction in other forums is permitted, provided the original author(s) and the copyright owner are credited and that the original publication in this journal is cited, in accordance with accepted academic practice. No use, distribution or reproduction is permitted which does not comply with these terms. 